\title{
Canadian Guideline For Safe and Effective Use of Opioids for Chronic Non-Cancer Pain: Implications for pain physicians
}

\author{
Meldon Kahan MD CCFP FRCPC ${ }^{1}$, Angela Mailis-Gagnon MD MSc FRCPC(PhysMed) ${ }^{2}$, \\ Eldon Tunks MD CM (Psychiatry) FRCPC ${ }^{3}$
}

\begin{abstract}
$\mathrm{C}$ hronic pain is a serious public health concern, causing widespread suffering and disability, and increased health care costs (1). Potent opioids have become a mainstay of chronic pain treatment, and both the number of patients taking opioids and the mean dose per patient have increased substantially in North America. Unfortunately, this has been accompanied by marked increases in opioid-related deaths, diversion, misuse and addiction, generating concern among the public and the medical profession.

For a guideline to be credible, it should be based on a comprehensive search of controlled trials and other studies, supplemented by the perspectives of experienced clinicians and opinion leaders. It should address questions important to public health and provide practical guidance to clinicians. These goals have been achieved in the recently published "Canadian Guideline for Safe and Effective Use of Opioids for Chronic Non-Cancer Pain" (2).

Under the umbrella of the Federation of Medical Regulatory Authorities of Canada, the National Opioid Use Guideline Group was created in 2008 to collaborate on guideline development and implementation. A core research group was formed, which conducted a systematic review of the effectiveness of opioids for chronic noncancer pain (CNCP), as well as focused reviews on topics such as medical complications of opioids and use of opioids in specific populations. The core group wrote an initial draft of the guideline. A 49-member panel that included physicians from family medicine, physiatry, neurology and addiction medicine, and various other health care providers, reviewed the draft and provided feedback through a structured approach. All major regions of Canada were represented on the panel, which included members of national organizations such as the Canadian Pain Society. The panel achieved consensus on 24 recommendations. Some highlights of the guideline are provided below.
\end{abstract}

\section{INDICATIONS}

The guideline suggests that opioids should, in most cases, be reserved for nociceptive or neuropathic pain conditions for which opioids have been shown to be effective.

\section{BASELINE ASSESSMENT}

The guideline advises that patients being considered for opioid therapy should undergo a comprehensive pain assessment, and a careful history of substance use and mental illness. For patients not well known to the physician, brief screening questionnaires or urine drug screens might help identify patients at high risk for addiction.

\section{TITRATION}

The guideline recommends slow and gradual titration to avoid excessive maintenance doses and acute complications. During each titration, the physician should enquire about mood, function, side effects, compliance and analgesic response to opioids.

\section{OPTIMAL DOSE}

The guideline defines the optimal opioid dose to be that which improves function and/or reduces pain severity by at least 30\%, with minimal analgesic benefit from additional dose increases, and no major side effects or complications.

\section{'WATCHFUL DOSE'}

The guideline recommends a 'watchful dose' of $200 \mathrm{mg}$ morphine equivalent per day (MED). Data extracted from a systematic review of opioid efficacy (3) demonstrated that mean doses used in controlled trials were well below $200 \mathrm{mg}$ MED: oxycodone $66 \mathrm{mg}$ and morphine $56 \mathrm{mg}$ for nociceptive pain; and oxycodone $81 \mathrm{mg}$ and morphine $92 \mathrm{mg}$ for neuropathic pain. Furthermore, there is evidence that opioid side effects and complications are dose related, including sleep apnea, hyperalgesia, sedation and overdose. A recent case-controlled study (4) demonstrated that the risk of opioid-related overdose was 2.9 times higher for those on a prescribed dose of $200 \mathrm{mg}$ MED or higher, relative to those on a dose of lower than $20 \mathrm{mg}$ MED.

\section{TAPERING}

Tapering is indicated when the patient exhibits a suboptimal analgesic response to an adequate trial of opioid therapy. In observational studies, patients who continued to experience severe pain and disability despite opioid therapy reported improvements in mood and pain ratings with tapering (5-7). This may be due to resolution of hyperalgesia, opioid-induced dysphoria or withdrawal-mediated pain, or the counselling that accompanied the tapering.

\section{HIGH RISK FOR MISUSE OR ADDICTION}

Two major risk factors for opioid misuse and addiction are a personal or family history of addiction, and a concurrent mood and anxiety disorder. With high-risk patients, opioids should be reserved for welldefined nociceptive or neuropathic pain conditions that would normally require opioid therapy and have not responded to nonopioid treatments. If opioids are used, they should be titrated slowly with frequent dispensing and close monitoring for signs of misuse.

\section{SPECIAL POPULATIONS}

The guideline recognizes that individuals vary widely in their response to opioids, depending on age, psychiatric status and other factors. Serious harms can be avoided if physicians take these factors into account when prescribing. For example, elderly patients have low rates of addiction, but opioid titration must be slow and gradual to avoid

${ }^{1}$ Department of Family Medicine, University of Toronto; Addiction Medicine Service, Department of Family Medicine, St Joseph's Health Centre;

${ }^{2}$ Department of Medicine, Division of Physiatry, Institute of Medical Science, University of Toronto; Comprehensive Pain Program, Toronto

Western Hospital; ACTION Ontario, Centre for the Study of Pain, Toronto; ${ }^{3}$ Department of Psychiatry, McMaster University, Hamilton;

Canadian Memorial Chiropractic College, Toronto, Ontario

Correspondence: Dr Meldon Kahan, Department of Family Medicine, East Wing, 30 The Queensway, St Joseph's Health Centre, Toronto,

Ontario M6R 1B5. Telephone 416-530-6860, fax 416-530-6106, e-mail kahanm@stjoe.on.ca 
overdoses and falls. Patients with concurrent anxiety and mood disorders tend to demonstrate a weaker analgesic response to opioids, are often on sedating medications, and are at greater risk for opioid misuse and addiction. Therefore, careful patient selection, titration and monitoring are required. For patients with both chronic pain and addiction, the guideline outlines three management options: structured opioid therapy, opioid agonist therapy with methadone or buprenorphine, and abstinence-based therapy. Opioid-addicted patients typically experience improved mood and pain when their opioid addiction is treated.

Important gaps in knowledge remain. For example, we know little about the long-term effectiveness and safety of opioid therapy. Observational studies have reported disturbing and paradoxical results. For example, one study (8) found that prescribing opioids early following a back injury was associated with a longer-term opioid prescription at higher doses, with only a minority of patients showing clinically important improvements in pain and function. Additionally, epidemiological studies from Denmark $(9,10)$ found that patients on long-term opioids continued to report persistent and significant pain, poor self-rated health, lack of employment, increased use of health services and lower quality of life.

\section{PHYSICIAN QUESTIONS AND CONCERNS REGARDING THE GUIDELINE}

During a workshop on the guideline at the Canadian Pain Society Conference held in Calgary, Alberta, in May 2010, some physicians raised questions and concerns. Select questions and answers are provided below.

\section{Is the guideline now the standard of care, and are physicians at medico-legal risk if they do not follow its recommendations? Currently, the guideline has no regulatory status. While its develop- ment was overseen by medical regulators, the guideline is now housed in the Michael G DeGroote National Pain Centre at McMaster University (Hamilton, Ontario), which is an independent academic institution. However, it is conceivable that in the future, regulatory authorities will use the guideline as a standard of care for assessing medical practices. In our view, this will benefit physicians because they will be protected from the arbitrary opinions of medical auditors and peer assessors. The guideline provides the beginning of a framework to guide clinicians, policy makers and regulatory bodies with evidence- based and expert opinion.}

Will third-party payers use the guideline to stop reimbursing claims for opioid doses of greater than $200 \mathrm{mg}$ MED?

One of the goals of the present commentary is to discourage rigid interpretations by third-party payers by explaining what the guideline does and does not do. The watchful dose is not intended as a firm limit but as a guidepost to prompt the clinician to carefully reassess the patient's response to opioid therapy and the overall treatment plan. The guideline acknowledges that doses of greater than $200 \mathrm{mg}$ MED are sometimes justified. The express purpose of the guideline is not to lay down rules but to promote opioid prescribing that is informed by evidence, consensus of experienced clinicians, and the best interests of patients and clinicians.

\section{Will the guideline's focus on addiction have a chilling effect on} opioid prescribing?

Recent evidence suggests that physicians are already very concerned about opioid misuse, addiction and overdose, and that these concerns reflect their own clinical experiences rather than what they read in the media or medical literature (11). In our opinion, physicians will become less concerned about addiction as they adapt the clinical practices outlined in the guideline including careful patient selection, dose titration and monitoring, and protocols for identifying and managing addiction.

The guideline is very long and detailed. Will it be useful for busy clinicians?

Admittedly, the guideline in its current form is long and cumbersome. However, the National Faculty coordinated by the Michael G DeGroote National Pain Centre is pursuing a dissemination strategy involving community workshops, office materials and clinical summaries of the guideline to make it accessible and user friendly.

Perhaps the greatest benefit of the guideline is that, by providing a balanced perspective regarding the role of opioids in CNCP management, nonopioid therapies will finally get the attention they deserve. Opioids are important but, overall, they are of modest clinical benefit, and they are associated with significant side effects and complications. Other therapies are also effective and safe, yet many Canadians do not have access to comprehensive pain clinics, nonopioid medications or psychotherapeutic treatments. Despite controversies about opioids, the pain field is unified in its recognition of the urgent need for improved funding and greater access to comprehensive CNCP treatment.

DISCLAIMER: Two of the authors (MK and AMG) were core researchers for the guideline. However, this commentary is not a product of the National Opioid Use Guideline Group, and the authors take sole responsibility for its content.

\section{REFERENCES}

1. Moulin DE, Clark AJ, Speechey M, et al. Chronic pain in Canada prevalence, treatment, impact and the role of opioid analgesia. Pain Res Manag 2002;7:179-84.

2. National Pain Centre, McMaster University. Canadian Guideline for Safe and Effective Use of Opioids for Chronic Non-Cancer Pain. $<$ www.nationalpaincentre.mcmaster.ca/opioid $>$ (Accessed on August 25, 2010).

3. Furlan AD, Sandoval JA, Mailis-Gagnon A, et al. Opioids for chronic noncancer pain: A meta-analysis of effectiveness and side effects. CMAJ 2006;174:1589-94.

4. Gomes T, Mandami M, Dhalla I, Paterson M, Juurlink D. Opioid dose and drug-related mortality in patients with nonmalignant pain. Arch Intern Med 2011;171:686.

5. Baron MD, McDonald PW. Significant pain reduction in chronic pain patients after detoxification from high-dose opioids. J Opioid Manag 2006:2:277-82.

6. Crisostomo RA, Schmidt JE, Hooten WM, Kerkvliet JL, Townsend CO, Bruce BK. Withdrawal of analgesic medication for chronic low-back pain patients: Improvement in outcomes of multidisciplinary rehabilitation regardless of surgical history. Am J Phys Med Rehabil 2008;87:527-36.

7. Hooten WM, Townsend CO, Sletten CD, Bruce BK, Rome JD. Treatment outcomes after multidisciplinary pain rehabilitation with analgesic medication withdrawal for patients with fibromyalgia. Pain Med 2007;8:8-16.

8. Franklin GM, Rahman EA, Turner JA, Daniell WE, Fulton-Kehoe D. Opioid use for chronic low back pain: A prospective, population-based study among injured workers in Washington state, 2002-2005. Clin J Pain 2009;25:743-51.

9. Eriksen J, Sjorgren P, Bruera E, Ekholm O, Rasmussen NK. Critical issues on opioids in chronic non-cancer pain: An epidemiological study. Pain 2006;125:172-9.

10. Jensen MK, Thomsen AB, Hoisted J. 10-year follow-up of chronic non-malignant pain patients: Opioid use, health related quality of life and health care utilization. Pain 2006;10:423-33.

11. Wenghofer E, Wilson L, Kahan M, et al. Survey of Ontario primary care physicians' experiences with opioid prescribing. Can Fam Physician 2011;57:324-32. 


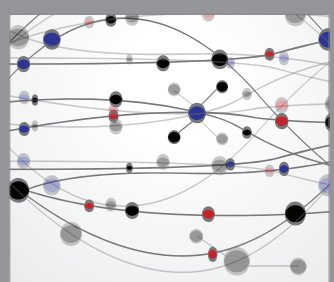

The Scientific World Journal
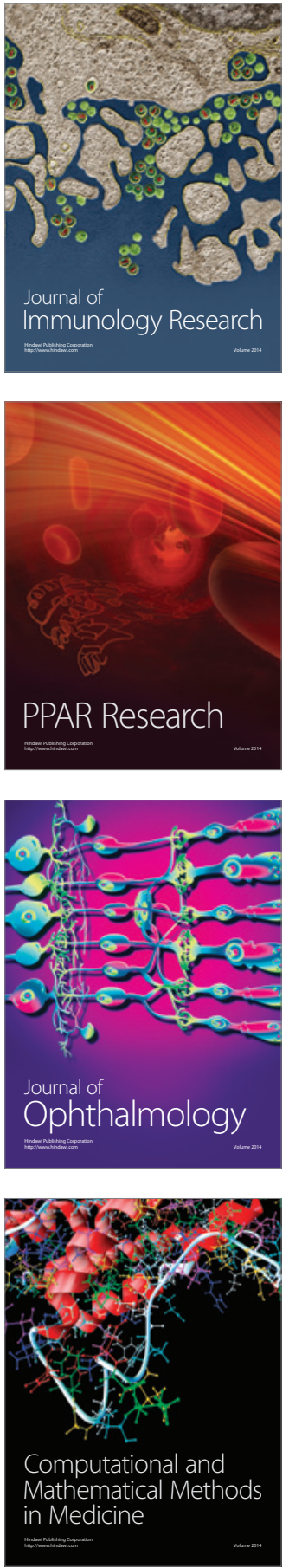

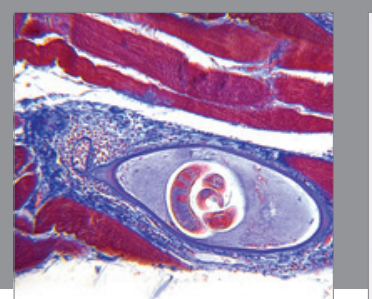

Gastroenterology Research and Practice

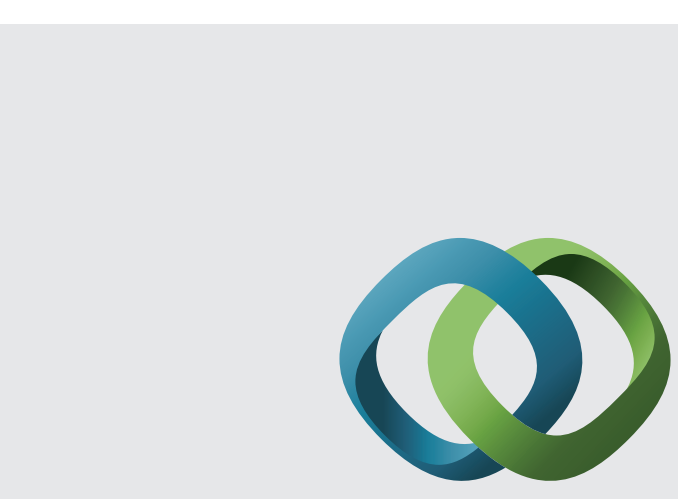

\section{Hindawi}

Submit your manuscripts at

http://www.hindawi.com
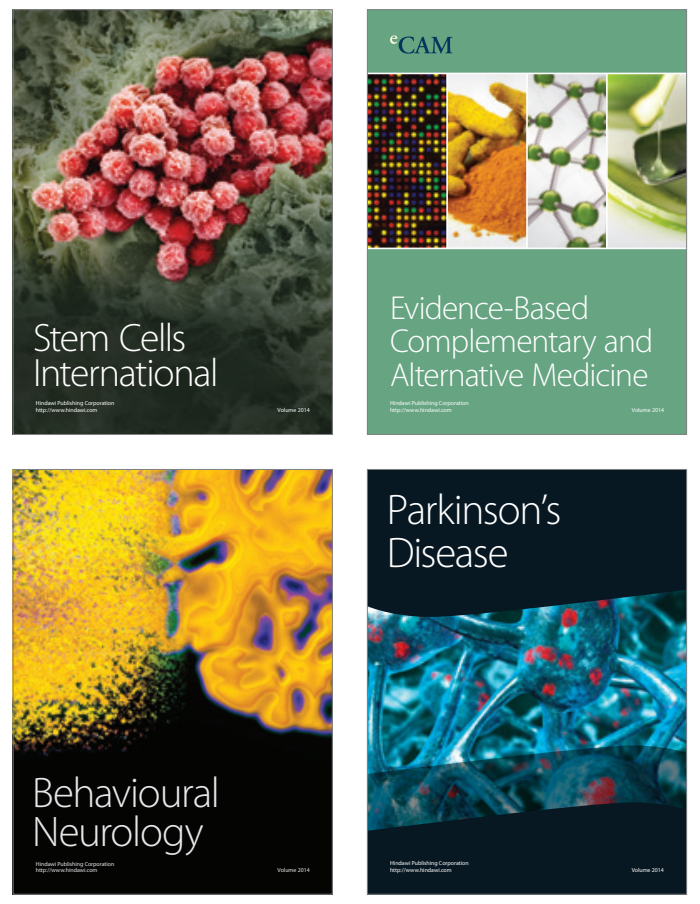
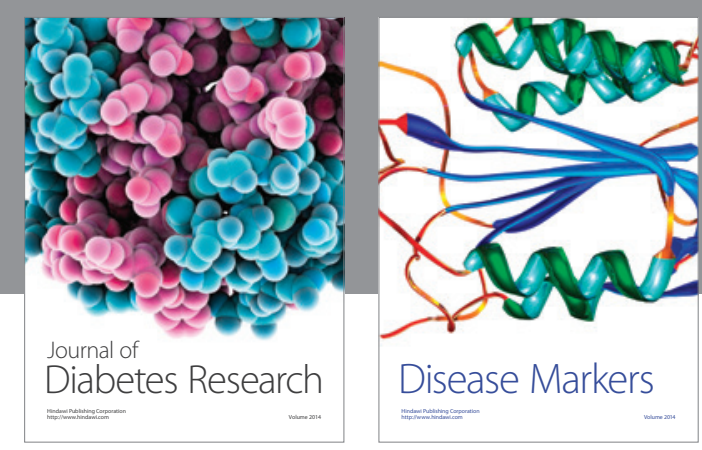

Disease Markers
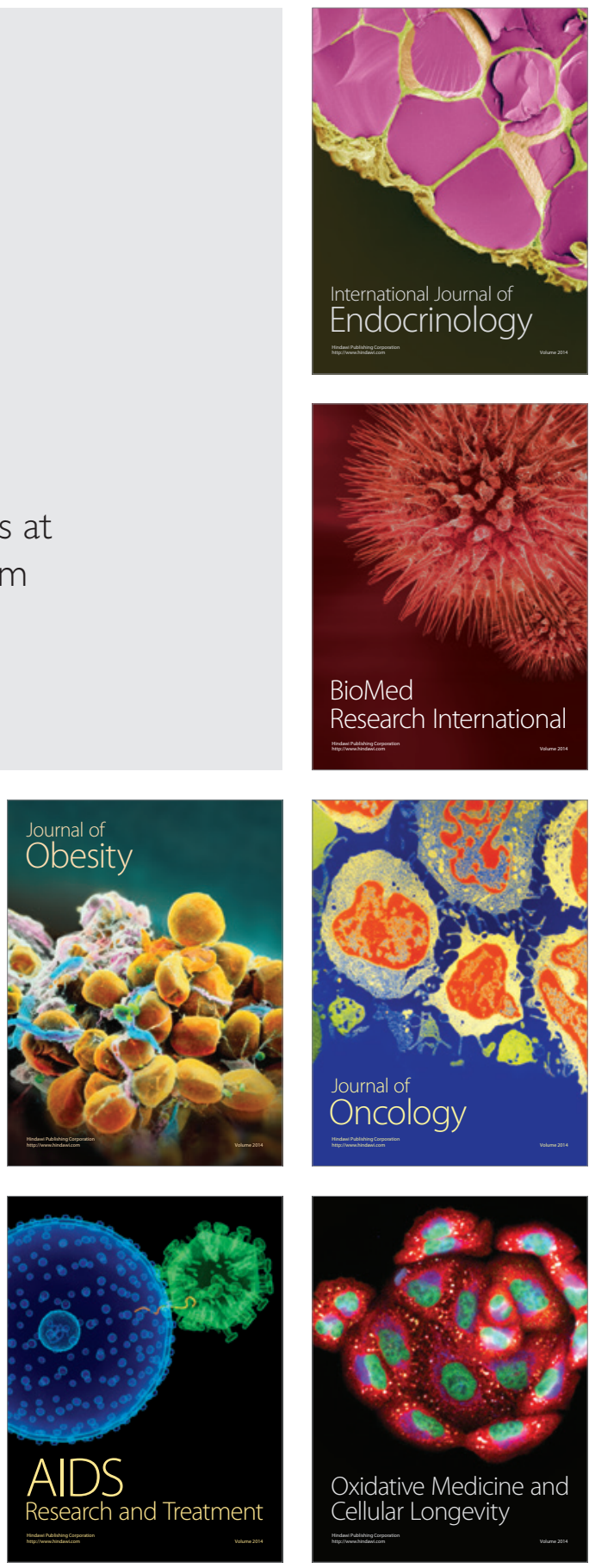